\title{
Effects of azithromycin and tanomastat on experimental bronchiolitis obliterans
}

\author{
Katharina Krenn, MD, ${ }^{a}$ Matthias Gmeiner, MD, PhD, ${ }^{b}$ Patrick Paulus, MD,${ }^{b, c}$ Nezir Sela, MD, ${ }^{b}$ \\ Linda Torres, MD, ${ }^{\mathrm{b}}$ Karin Zins, PhD, ${ }^{\mathrm{b}}$ Gerhard Dekan, MD, ${ }^{\mathrm{d}}$ and Seyedhossein Aharinejad, MD, PhD ${ }^{\mathrm{b}, \mathrm{e}}$
}

Objective: Azithromycin has become a standard of care in therapy of bronchiolitis obliterans following lung transplantation. Matrix metalloprotease-9 broncho-alveolar lavage levels increase in airway neutrophilia and bronchiolitis obliterans. Interleukin-17 may play a role in lung allograft rejection, and interleukin-12 is downregulated in bronchiolitis obliterans. Whether these mechanisms can be targeted by azithromycin remains unclear.

\begin{abstract}
Methods: Bronchiolitis obliterans was induced by transplantation of Fischer F344 rat left lungs to Wistar Kyoto rats. Allografts with azithromycin therapy from day 1 to 28 or 56 and mono- or combination therapy with the broad-spectrum matrix metalloprotease inhibitor tanomastat from day 1 to 56 were compared to control allografts and isografts. Graft histology was assessed, and tissue cytokine expression studied using Western blotting and immunofluorescence.
\end{abstract}

Results: The chronic airway rejection score in the azithromycin group did not change between 4 and 8 weeks after transplantation, whereas it significantly worsened in control allografts $(P=.041)$. Azithromycin + tanomastat prevented complete allograft fibrosis, which occurred in $40 \%$ of control allografts. Azithromycin reduced interleukin-17 expression $(P=.049)$ and the number of $\mathrm{IL}^{-17^{+}} / \mathrm{CD}^{+}$lymphocytes at 4 weeks, and active matrix metalloprotease-9 at 8 weeks $(P=.017)$, and increased interleukin-12 expression $(P=.025)$ at 8 weeks following transplantation versus control allografts.

Conclusions: The expression of interleukin-17 and matrix metalloprotease- 9 in bronchiolitis obliterans may be attenuated by azithromycin, and the decrease in interleukin- 12 expression was prevented by azithromycin. Combination of azithromycin with a matrix metalloprotease inhibitor is worth studying further because it prevented complete allograft fibrosis in this study. (J Thorac Cardiovasc Surg 2015;149:1194-202)

See related commentary on pages $1203-4$.

Bronchiolitis obliterans (BO) following lung transplantation is one of the major factors compromising long-term survival. It is the leading cause of death between 3 and 5 years after lung transplantation in adults, and its clinical correlate $\mathrm{BO}$ syndrome (BOS) is prevalent in about $50 \%$ of recipients surviving 5 years. ${ }^{1}$ Risk factors of BO include nonspecific alloimmune-independent and alloimmunedependent mechanisms ${ }^{2}$ that are already triggered by ischemia-reperfusion injury. Proinflammatory cytokines that are upregulated in primary graft dysfunction can

From the Departments of Anesthesia and General Intensive Care ${ }^{\mathrm{a}}$ and Cardiovascular Research, ${ }^{\mathrm{b}}$ Medical University of Vienna; Department of Anesthesiology, ${ }^{\mathrm{c}}$ Intensive Care Medicine and Pain Therapy, Goethe University Hospital, Frankfurt, Germany; and Departments of Pathology ${ }^{\mathrm{d}}$ and Cardiac Surgery, ${ }^{\mathrm{e}}$ Medical University of Vienna, Vienna, Austria.

This study was funded by grant No. 13196 of the Austrian National Bank to S.A.

Disclosures: Authors have nothing to disclose with regard to commercial support.

Received for publication May 24, 2014; revisions received Nov 16, 2014; accepted for publication Nov 29, 2014; available ahead of print Jan 13, 2015.

Address for reprints: Seyedhossein Aharinejad, MD, PhD, Department of Cardiac Surgery, Medical University of Vienna, Waehringer Guertel 18-20, A-1090 Vienna, Austria (E-mail: seyedhossein.aharinejad@meduniwien.ac.at).

$0022-5223 / \$ 36.00$

Copyright (c) 2015 by The American Association for Thoracic Surgery http://dx.doi.org/10.1016/j.jtcvs.2014.11.088 increase HLA-II antigen expression in the graft, thus triggering donor-specific alloimmunity. ${ }^{3}$ Each additional insult, including acute rejection, infection, or gastroesophageal reflux disease, further increases the risk of the development of a persistent self-promoting inflammatory reaction that may lead to maladaptive excessive fibroproliferation in the small airways, resulting in the histologic picture of $\mathrm{BO}$. In the development of $\mathrm{BO}$, inflammatory reactions and tissue remodeling are intricately linked by the interaction of recipient immunity and structural lung cells, which may also promote inflammation. ${ }^{4}$ The overall result is progressive loss of graft function with airflow obstruction.

Matrix metalloproteases (MMPs) are produced by immunologically active cells and involved in matrix degradation in fibrotic tissue remodeling. MMP-9 is produced by neutrophils and macrophages, and its levels are increased in broncho-alveolar lavage (BAL) fluid of patients with airway neutrophilia that is associated, for example, with BOS or infection. ${ }^{5,6}$ Interleukin (IL)-17 is upregulated in pulmonary allograft rejection ${ }^{7,8}$ and co-regulates MMP-9 expression. ${ }^{9}$ The IL-17 antagonist IL-12 has been reported to be downregulated in BAL fluid of BOS patients. ${ }^{10}$ In addition, patients with BOS had increased numbers of $\mathrm{T}$ cells secreting IL-17 and interferon (IFN)- $\gamma,{ }^{11}$ versus stable lung transplant recipients. 


$$
\begin{array}{ll}
\text { Abbreviations and Acronyms } \\
\text { Allo } & =\text { allograft } \\
\text { AZI } & =\text { azithromycin } \\
\text { AZI+tano } & =\text { azithromycin+tanomastat } \\
\text { BAL } & =\text { broncho-alveolar lavage } \\
\text { BALT } & =\text { bronchus-associated lymphoid tissue } \\
\text { BO } & =\text { bronchiolitis obliterans } \\
\text { BOS } & =\text { BO syndrome } \\
\text { CINC } & =\text { cytokine-induced neutrophil } \\
& \text { chemoattractant } \\
\text { DAPI } & =4^{\prime}, 6 \text {-diamidino-2-phenylindole } \\
\text { EVG } & =\text { elastica van Gieson } \\
\text { HE } & =\text { hematoxylin-eosin } \\
\text { IFN } & =\text { interferon } \\
\text { IL } & =\text { interleukin } \\
\text { Iso } & =\text { isograft } \\
\text { MMP } & =\text { matrix metalloprotease } \\
\text { SD } & =\text { standard deviation } \\
\text { TNF- } \alpha & =\text { tumor necrosis factor alpha } \\
\text { WKY } & =\text { Wistar Kyoto }
\end{array}
$$

The macrolide antibiotic azithromycin (AZI) has become an important therapeutic option for patients with BOS and improves their survival ${ }^{12}$; in particular, those with airway neutrophilia benefit from AZI. ${ }^{13}$ A recent meta-analysis of 10 studies on AZI therapy for BOS showed a significant improvement in lung function over an average observation period of 7 months. ${ }^{14} \mathrm{~A}$ clinical trial of prophylactic AZI treatment demonstrated a decreased incidence of BOS. ${ }^{15}$ Multiple studies in vitro and in vivo have shown immunomodulatory effects of AZI and its ability to counteract bacterial biofilm generation and gastroesophageal reflux. ${ }^{16}$ Recently, BAL samples of lung transplant recipients have been studied before and after initiation of AZI, and a differential regulation of a number of cytokines by AZI was shown. ${ }^{5}$ In contrast to BAL, a human lung tissue sample representative of $\mathrm{BO}$ is difficult to obtain, so a model system may help to further understand the action of AZI in vivo. As human BO develops in distal airways, we chose an orthotopic left lung transplantation model in rats for our study instead of a tracheal allograft model. Transplantation of Fischer F344 lungs to Wistar Kyoto (WKY) rats leads to acute rejection and subsequent chronic changes with predominant vascular rejection, but BO-like lesions develop in about $70 \%$ to $80 \%$ of the animals at 60 days following transplantation. ${ }^{17-19}$ In the current study, we investigated the effects of prophylactic AZI on BO in this model at 4 and 8 weeks posttransplant, corresponding to acute inflammatory and chronic stages of allograft dysfunction. No immunosuppression other than a single dose of prednisolone at transplantation to avoid hyperacute rejection on the first day was given to determine the immunomodulatory effects of AZI alone. To investigate whether the combination of AZI with a broad-spectrum MMP inhibitor could be beneficial in preventing BO, a combination of AZI and tanomastat was evaluated prophylactically for 8 weeks following transplantation.

\section{MATERIAL AND METHODS \\ Animals}

Pathogen-free, major histocompatibility complex RT1-mismatched male rats, that is, F344 and WKY obtained from Harlan Winkelmann (Borchen, Germany; 250-300 $\mathrm{g}$ at transplantation), were utilized in this study. ${ }^{20}$ This study was approved by the Institutional Biomedical Ethics Committee and the rats were housed in the Center for Biomedical Research at the Medical University of Vienna in accordance with the guidelines described in the Guide for the Care and Use of Laboratory Animals published by the National Institutes of Health. The following groups were studied: F344-WKY allografts ( 4 weeks $n=5,8$ weeks $n=5$ ), WKY-WKY isografts ( 4 weeks $n=4,8$ weeks $n=4$ ), azithromycin in allografts (AZI group; 4 weeks $n=4,8$ weeks $n=4$ ), and broad-spectrum MMP inhibitor tanomastat (BAY-12-9566, kindly gifted by Bayer Healthcare Austria, Vienna) alone or in combination with AZI for 8 weeks in allografts (Tano group, $\mathrm{n}=5$; AZI +tano group, $\mathrm{n}=4$ ). AZI was started intraperitoneally (i.p.) on the first day following transplantation, repeated once daily for 3 days at a dose of $50 \mathrm{mg} / \mathrm{kg}$ body weight, and then continued i.p. cycled 3 times per week (Monday-Wednesday-Friday). Tanomastat was administered orally at a dose of $15 \mathrm{mg} / \mathrm{kg}$ body weight ${ }^{21}$ once per day starting on the first day following transplantation.

\section{Transplantation Procedure}

The orthotopic transplantation of left lung isografts (WKY-WKY) or allografts (F344-WKY) was performed as described. ${ }^{17,22}$ The heart and lungs were perfused with Perfadex (Vitrolife, Gothenburg, Sweden) with addition of heparin, prednisolone (Solu-Dacortin; Merck, Vienna, Austria), and epoprostenol (Flolan; Glaxo Smith Kline, Uxbridge, United Kingdom) via the right-ventricular outflow tract. A cuff technique was employed for the anastomoses. ${ }^{23}$ The recipients received a single steroid dose (50 mg prednisolone) and single-shot antibiotic prophylaxis with $60 \mathrm{mg}$ piperacillin/tazobactam i.p. immediately before transplantation. No other immunosuppressive therapy was given at any time.

\section{Histologic Analysis}

The transplanted lung was equally divided in an upper half that was fixed in 5\% paraformaldehyde and a lower half that was frozen in liquid nitrogen for protein extraction. Histologic slides were stained with hematoxylineosin and elastica van Gieson (EVG) and examined by a pathologist (G.D.) in a blinded fashion. Histologic findings were attributed to groups of absent, low-grade, high-grade, and fibrotic chronic vascular and airway changes as described. ${ }^{18}$ The categories of chronic vascular rejection were as follows: low-grade chronic vascular rejection: occlusion of small vessels with mononuclear infiltrate and fibrous tissue; high grade: vascular sclerosis of small and medium-sized arteries and veins with fibrointimal thickening; and fibrotic chronic vascular changes: complete allograft fibrosis. The categories of chronic airway rejection were as follows: low-grade chronic airway rejection: initial signs of intraluminal granulation tissue polyps in more than one terminal bronchiole or loose subepithelial fibrin structures around terminal bronchioles; high grade: $\mathrm{BO}$ with fibrosis of the submucosa of terminal bronchioles with partial or complete luminal occlusion; and chronic fibrotic airway changes: complete allograft fibrosis.

\section{Immunofluorescence Staining}

Immunofluorescence was performed on formalin-fixed paraffinembedded lung tissue sections. After deparaffinization, antigen retrieval was performed in citric acid ( $\mathrm{pH} \mathrm{6.0)}$ for 20 minutes at $80^{\circ} \mathrm{C}$. Then the 

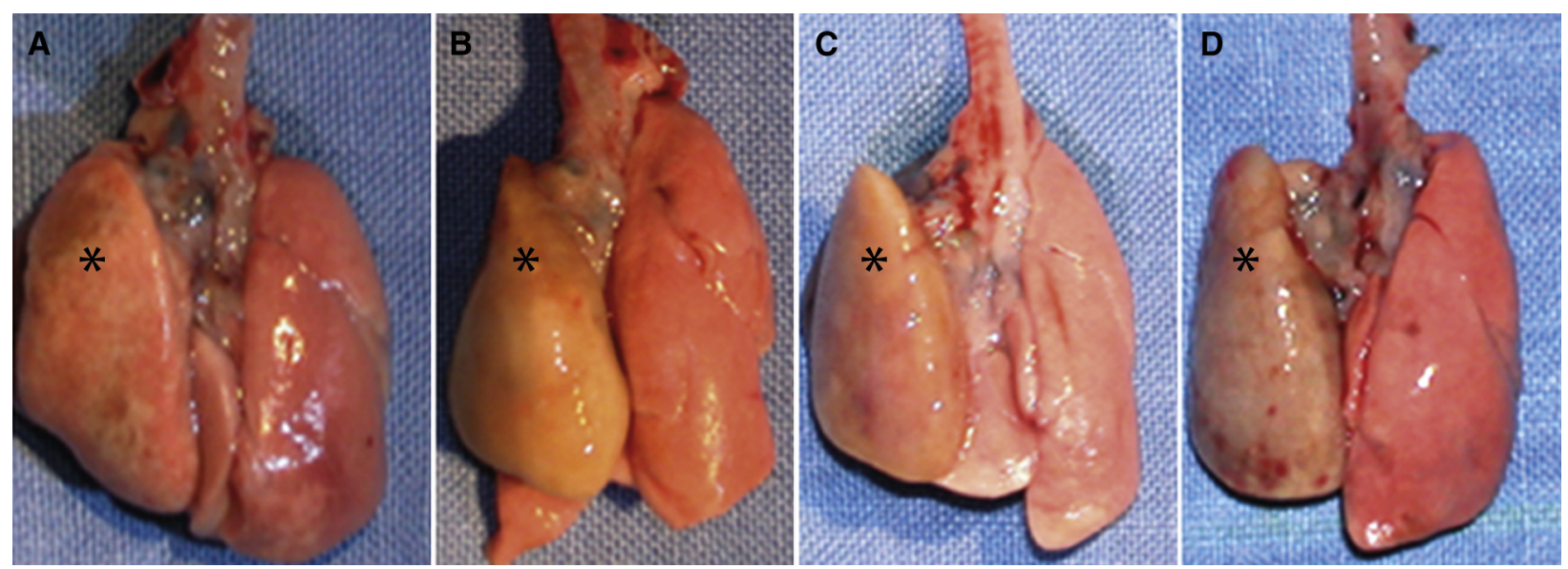

FIGURE 1. Macroscopic aspect of transplanted lungs. Macroscopic images of the posterior aspect of the lungs at 8 weeks posttransplant. The asterisk indicates the left transplanted lung. A, Isograft control; B, allograft control; C, AZI therapy; D, AZI+tano therapy.

sections were blocked for 1 hour and thereafter incubated with monoclonal mouse anti-rat CD8 (1:100; Abcam, Cambridge, United Kingdom) and polyclonal rabbit anti-rat IL-17 (1:50; Santa Cruz Biotechnology, Dallas, Tex) primary antibodies at $4{ }^{\circ} \mathrm{C}$ overnight. After washing the sections were incubated with $4^{\prime}, 6$-diamidino-2-phenylindole (DAPI) for 10 minutes, washed again and incubated with secondary goat anti-mouse antibody conjugated with phycoerythrin and goat anti-rabbit antibody conjugated with Alexa Fluor 488 (both 1:200) for 1 hour. Then the slides were washed and mounted with Permafluor (Thermo Fisher, Waltham, Mass). Sections were digitized with TissueFAXS 4.1 software (TissueGnostics Gmbh, Vienna, Austria) using a confocal IF microscope (LSM 510; Zeiss, Oberkochen, Germany). The staining of infiltrating lymphocytes was examined manually in the digitized slides using TissueFAXS Viewer 4.5 software (TissueGnostics). In a rectangular grid $(0.32 \times 0.45 \mathrm{~mm}$ per field of view $)$ single- and double-stained cells were counted in a blinded fashion at a magnification of $\times 400$.

\section{Cytokine Antibody Array}

The relative expression levels of 19 cytokines were measured using a ChemiArray rat cell lysate cytokine array kit (Chemikon, Eagle Close, Hampshire, United Kingdom) according to the manufacturer's protocol. Protein was isolated from lung tissue using the provided lysis buffer with addition of $1 \times$ Complete-EDTA-free protease inhibitor cocktail (Roche, Basle, Switzerland). Samples of each treatment or control group at 8 weeks following transplantation were pooled for analysis in the antibody array. Protein concentrations of the lysates were measured, and $250 \mu \mathrm{g}$ protein consisting of equal protein quantities of the single samples of each group were added to each array membrane after blocking with $1 \times$ blocking buffer for 30 minutes. After incubation overnight at $4^{\circ} \mathrm{C}$, membranes were washed; then the membranes were incubated for 2 hours with biotinylated antibody. After washing, the membranes were incubated with horseradish peroxidase conjugated streptavidin for 1 hour. Then the membranes were exposed to the detection buffer. The signal was obtained within $1 \mathrm{~h}$ using a chemiluminescence-sensitive film. Relative expression levels of each protein were quantified using ImageQuant Version 5.0 (Molecular Dynamics) software.

\section{Western Blotting}

Tissue lysates (100 $\mu \mathrm{g}$ protein/lane) were separated by a $10 \%$ to $12 \%$ sodium dodecylsulfate polyacrylamide gel electrophoresis before electrophoretic transfer onto nitrocellulose membrane (Bio-Rad Laboratories, Hercules, Calif). The blots were probed with polyclonal antibodies against MMP-9 (Millipore, Billerica, Mass), IL-17 (Santa Cruz Biotechnology), IL-12p40, IFN- $\gamma$, and MMP-2 (all 3 from Abcam) prior to incubation with horseradish peroxidase-conjugated anti-rabbit (IL-17, IFN- $\gamma$, MMP-2), anti-mouse (MMP-9), and anti-goat (IL-12) secondary antibodies. Proteins were detected using chemiluminescence (ECL, Amersham Pharmacia Biotech, Buckinghamshire, United Kingdom) and specific bands were quantified using ImageJ software, version $1.45 \mathrm{~s}$.

\section{Statistical Analysis}

Protein expression levels, histologic scores, and mean numbers of IL$17^{+} / \mathrm{CD}^{+}$cells per field of view were compared between the groups at 4 and 8 weeks following transplantation by nonparametric analysis of variance (Kruskal-Wallis test). Correlation was analyzed by Spearman rank test. Statistical analysis was performed using SAS version 9.3, and statistical significance was set at $P<.05$. Data are expressed as mean \pm standard deviation.

\section{RESULTS}

\section{Effects of AZI on Lung Allograft Histology}

Untreated allografts were shrunken, indurated, and had a yellowish aspect macroscopically (Figure 1). Isografts showed normal histology up to 8 weeks following transplantation, whereas control allografts showed signs of chronic vascular and airway rejection characterized by increased collagen deposition, obliteration of bronchioles and small vessels, and leukocyte infiltration at 8 weeks following transplantation (Figure 2). The histologic picture was not improved after 4 weeks of AZI versus control allografts. Chronic vascular and airway changes were slightly attenuated after 8 weeks in animals receiving AZI with reduced collagen deposition in EVG stains (Figure 2), but without statistically significant change in histologic score ${ }^{18}$ versus controls (Figure 3, Table 1). The chronic airway rejection score in AZI-treated animals did not change significantly between 4 and 8 weeks after transplantation, whereas it significantly worsened from 4 to 8 weeks after transplantation in control allografts $(P=.041)$. Complete allograft fibrosis occurred in $40 \%$ of control allografts versus $25 \%$ in the AZI group at 8 weeks following transplantation, which was not a statistically significant difference.

One group received AZI+tanomastat for 8 weeks following transplantation to assess the additional effect of broad-spectrum MMP inhibition. ${ }^{24}$ Treatment with 

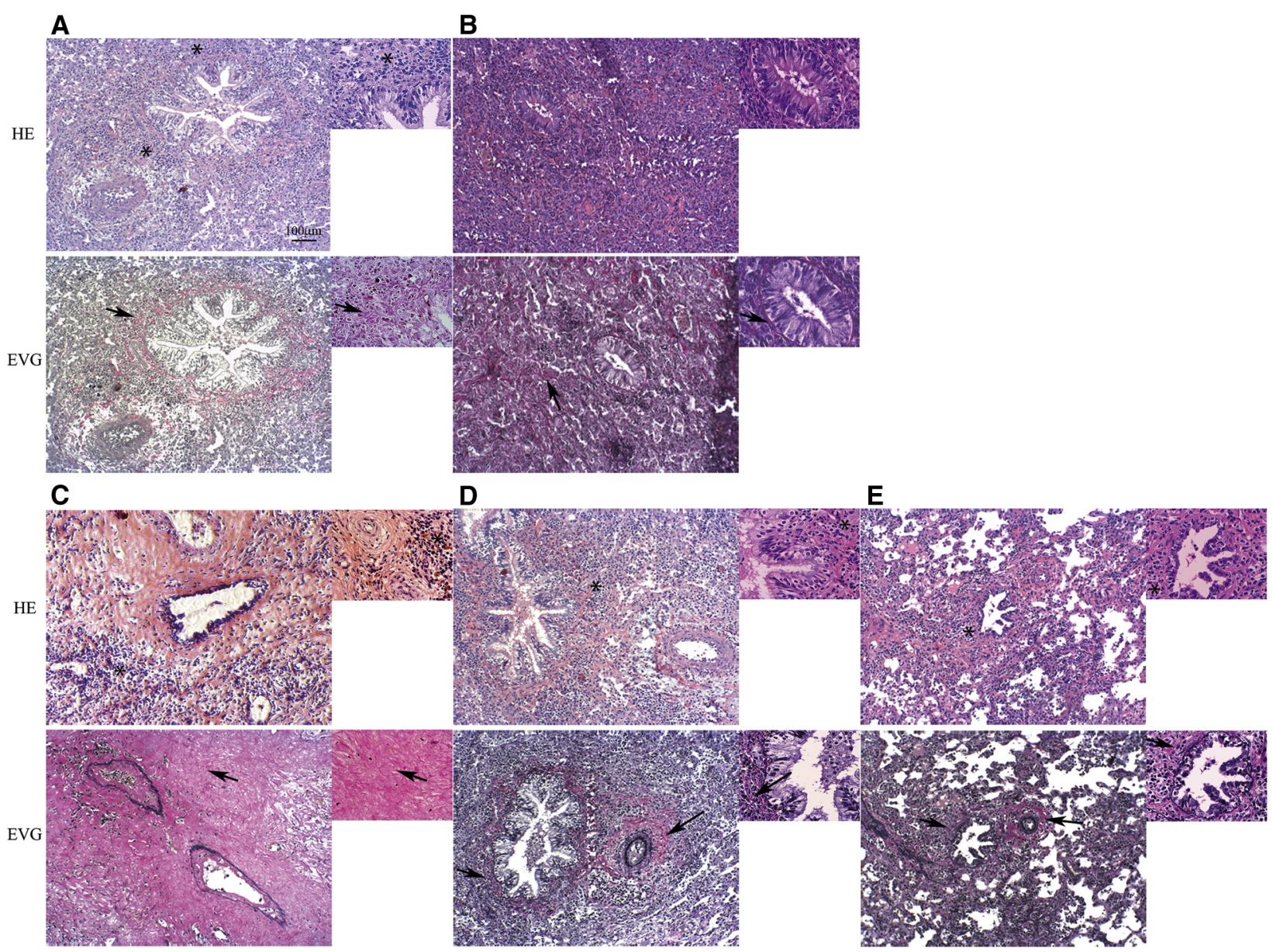

FIGURE 2. Histologic findings in transplanted lungs. Representative histologic images of lung allografts stained with HE for overview and EVG to stain collagen fibers. A, Allografts at 4 weeks following transplantation show dense leukocyte infiltration (asterisks), with only a small amount of collagen fibers (arrows in EVG images). B, Azithromycin group at 4 weeks after transplantation. C, At 8 weeks following transplantation, leukocyte infiltration (asterisks) is moderately decreased in control allografts, and increased deposition of collagen fibers is evident (arrows in EVG images). The azithromycin (D) and azithromycin+tanomastat groups (E) show less collagen deposition than the allograft controls (C). Original magnification $\times 100$ in (A-E) to the left; field at higher magnification within the same slide $(\times 400)$ to the right. HE, Hematoxylin-eosin; EVG, elastica van Gieson.

tanomastat alone for 8 weeks following transplantation failed to improve histology $(\mathrm{n}=5$; data not shown), so we aimed to investigate if a combination with AZI could be beneficial. Of note, in the AZI+tano group, no complete allograft fibrosis occurred after 8 weeks versus $40 \%$ in control allografts (Figure 3, Table 1). Chronic vascular $(P=.19)$ and airway rejection scores $(P=.15)$ were slightly lower in the AZI+tano than in the control allograft group. Collagen deposition was also slightly decreased in the AZI+tano versus control allograft group in EVG stains (Figure 2).

\section{Cytokine Antibody Array}

Tumor necrosis factor alpha (TNF- $\alpha$ ) was increased by factor 1.8 in allografts versus isografts at 8 weeks following transplantation, and further increased by factor 1.4 by Tano alone versus allografts. In the AZI group, TNF- $\alpha$ levels were reduced by factor 1.6 versus allografts and in the AZI +tano group TNF- $\alpha$ levels were similar to the allograft group. Furthermore, the cytokine-induced neutrophil chemoattractant (CINC)-3 was increased in allografts versus isografts by factor 24.1 and further increased by factor 1.5 in the Tano group as compared to allografts. In the AZI group, CINC-3 levels were similar to isografts, and in the AZI + tano group, CINC-3 levels were reduced by factor 2.5 versus allografts.

\section{Effects of AZI on IL-12, IFN- $\gamma$, IL-17, MMP-9, and MMP-2 Protein Expression}

At 8 weeks posttransplant, IL-12 was decreased in allografts versus isografts $(P=.053$; Figure $4, A)$. In the AZI group, IL-12 protein expression was significantly higher than in the allograft group at 8 weeks posttransplant $(P=.025)$ and similar to IL-12 levels of isografts at 8 
A

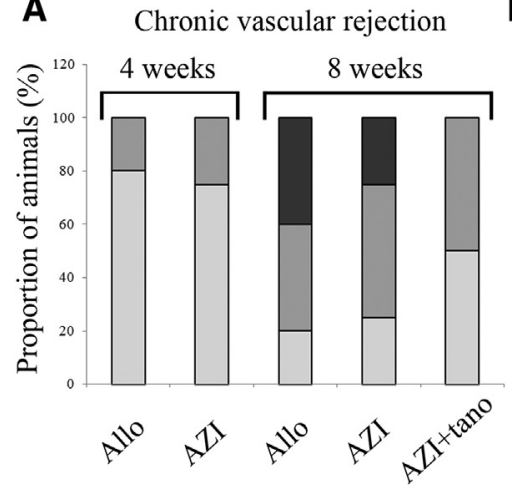

B

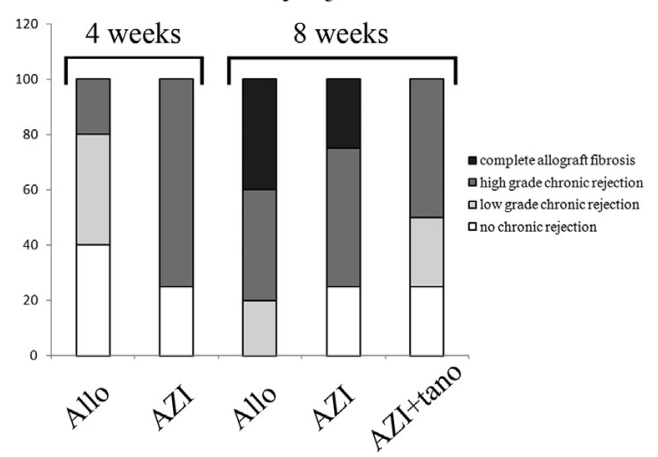

FIGURE 3. Scoring of chronic vascular and chronic airway rejection in transplanted lungs. Relative frequencies of histologic categories for chronic vascular and chronic airway rejection in the allograft control and therapy groups. A, Relative frequencies of degrees of chronic vascular rejection. B, Relative frequencies of degrees of chronic airway rejection (severe means BO). Allo, Control allografts $(\mathrm{n}=5$ at 4 and 8 weeks); $A Z I$, azithromycin treatment ( $=4$ at 4 and 8 weeks); $A Z I+$ tano, azithromycin+tanomastat treatment $(\mathrm{n}=4$ at 8 weeks $)$.

weeks. In the AZI+tano group, IL-12 was slightly increased versus allografts at 8 weeks posttransplant $(P=.12$; Figure 4, B).

IFN- $\gamma$ was significantly increased in allografts versus isografts at 4 weeks following transplantation $(P=.049$; Figure $4, B)$. However, at 8 weeks, IFN- $\gamma$ expression in allografts had decreased and was not different from that of isografts. AZI did not significantly change IFN- $\gamma$ expression at 4 or 8 weeks.

IL-17 protein expression was significantly reduced by AZI at 4 weeks following transplantation versus allografts $(P=.049$; Figure $4, C)$ and slightly decreased by AZI at 8 weeks $(P=.10)$.

Active MMP-9 protein was significantly increased in allografts versus isografts at 8 weeks $(P=.014$; Figure $4, D)$. In the AZI group, at 8 weeks, active MMP-9 was significantly decreased versus allograft controls at 8 weeks $(P=.017)$ and AZI animals at 4 weeks $(P=.034)$. No significant changes were found in proMMP-9 expression between all groups (Figure 4,E).

MMP-2 protein expression was significantly increased in allografts versus isografts at 4 and 8 weeks following transplantation $(P=.042$ and $P=.001$, respectively; Figure 4, $F)$. At 4 weeks, MMP-2 was slightly decreased in the AZI group versus allografts $(P=.059)$, whereas at 8 weeks, MMP-2 was significantly increased in the AZI and AZI+tano groups versus isografts $(P=.001$ and $P=.002$, respectively).

Immunofluorescent double-staining of IL-17 and CD8. $\mathrm{IL}-17^{+} / \mathrm{CD} 8^{+}$cell numbers per field of view were significantly higher in control allografts than in AZI-treated allografts at 4 weeks following transplantation $(P=.042$; Table 1). Representative double-stained cells are shown in Figure 5. Most IL-17-producing cells in control allografts were $\mathrm{CD} 8^{+}$. In isografts, $\mathrm{IL}-17^{+} / \mathrm{CD} 8^{+}$cells were rare $(2.0 \pm 1.6$ and $2.6 \pm 1.7$ at 4 and 8 weeks, respectively),

TABLE 1. Histologic categories of chronic rejection and numbers of $\mathrm{IL}_{-17} / \mathrm{CDB}^{+}$cells per field of view in the experimental groups

\begin{tabular}{|c|c|c|c|c|c|}
\hline Histologic category & $\begin{array}{l}\text { Allografts } 4 \text { weeks } \\
(n=5)\end{array}$ & $\begin{array}{c}\text { AZI } 4 \text { weeks } \\
\quad(n=4)\end{array}$ & $\begin{array}{l}\text { Allografts } 8 \text { weeks } \\
(n=5)\end{array}$ & $\begin{array}{c}\text { AZI } 8 \text { weeks } \\
(n=4)\end{array}$ & $\begin{array}{r}\text { AZI }+ \text { Tano } 8 \\
\text { weeks }(n=4) \\
\end{array}$ \\
\hline \multicolumn{6}{|l|}{ Chronic vascular rejection } \\
\hline No chronic rejection & 0 & 0 & 0 & 0 & 0 \\
\hline Low-grade chronic rejection & 4 & 3 & 1 & 1 & 2 \\
\hline High-grade chronic rejection & 1 & 1 & 2 & 2 & 2 \\
\hline Complete allograft fibrosis & 0 & 0 & 2 & 1 & 0 \\
\hline \multicolumn{6}{|l|}{ Chronic airway rejection } \\
\hline No chronic rejection & 2 & 1 & 0 & 1 & 1 \\
\hline Low-grade chronic rejection & 2 & 0 & 1 & 0 & 1 \\
\hline High-grade chronic rejection & 1 & 3 & 2 & 2 & 2 \\
\hline Complete allograft fibrosis & 0 & 0 & 2 & 1 & 0 \\
\hline \multicolumn{6}{|c|}{ Immunofluorescent double-staining of IL-17 and CD8 } \\
\hline $\begin{array}{l}\mathrm{IL}-17^{+} / \mathrm{CD} 8^{+} \text {cells per field of } \\
\text { view }(\text { mean } \pm \mathrm{SD})\end{array}$ & $5.8 \pm 1.9$ & $2.7 \pm 1.4^{*}$ & $6.7 \pm 3.6$ & $4.3 \pm 2.8$ & $5.2 \pm 3.2$ \\
\hline
\end{tabular}



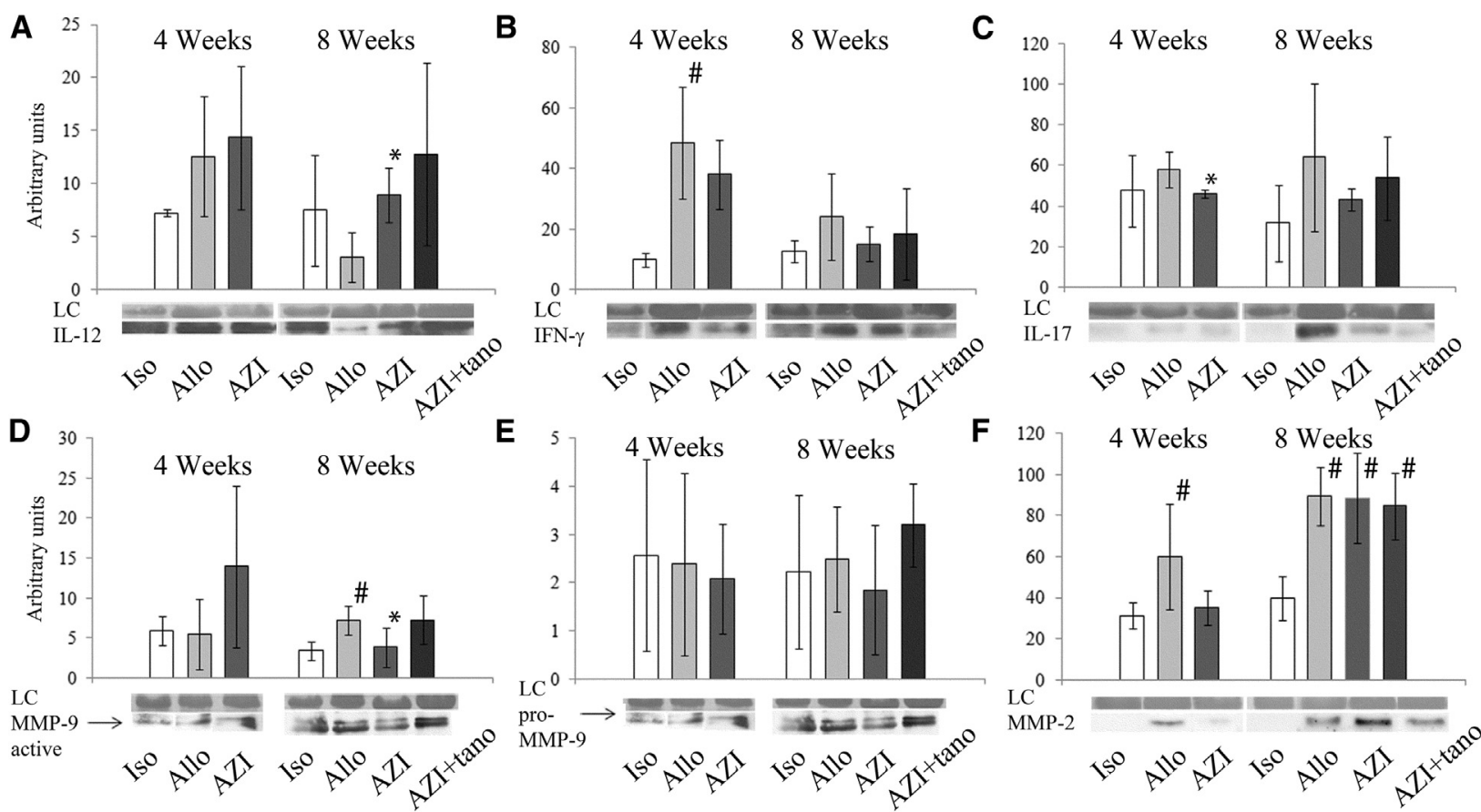

FIGURE 4. Lung tissue protein expression of IL-12, IFN- $\gamma$, IL-17, MMP-9, and MMP-2. Results of Western blotting of protein extracted from whole lung tissue of the studied groups. Protein expression levels of IL-12 (A), IFN- $\gamma$ (B), IL-17 (C), active and proMMP-9 (D and E) and MMP-2 (F), representative specific bands and loading controls are shown for each group. All data are presented as arbitrary units. *Indicates significantly different versus allografts at the same time point; \#indicates significantly different versus isografts at the same time point. $L C$, Loading control; IL-12, interleukin-12; $I F N-\gamma$, interferon- $\gamma ; I L-17$, interleukin-17; Iso, isograft; Allo, allograft; AZI, azithromycin treatment; AZI+tano, azithromycin+tanomastat treatment; $M M P$, matrix metalloprotease.

but the highest numbers of $\mathrm{CD} 8^{+}$cells without IL-17 production were found in isografts $(5.8 \pm 3.5$ and $6.0 \pm 4.9$ at 4 and 8 weeks, respectively).

Comment. This study showed for the first time that AZI treatment directly decreases IL-17 protein expression in lung tissue and not only the IL-17-induced expression of IL- 8 during lung allograft rejection. In addition, we could show by immunofluorescent double-staining that most IL-17 producing cells in control allografts were $\mathrm{CD} 8^{+}$lymphocytes and that AZI significantly reduced the number of $\mathrm{IL}-17^{+} / \mathrm{CD}^{+}$cells in lung tissue at 4 weeks following transplantation. In addition, recently a clinical study reported that AZI therapy reduced the number of $\mathrm{IL}-17^{+}$cells in lymphocytic bronchiolitis that appeared to be mostly $\mathrm{CD}^{+}{ }^{+}$cytotoxic T lymphocytes (Tc17) cells. ${ }^{25}$ In inflammatory lung diseases, Th17 lymphocytes, Tc17 cells, invariant natural killer T cells, $\gamma \delta$ T cells, and lymphoid tissue-induced T cells may be sources of IL-17, and the common consequence is a severe neutrophilic response at the site of IL-17 production that does not respond to immunosuppression or steroids. ${ }^{26}$ Previous reports have shown that IL-17 is increased in the BAL fluid of lung transplant patients with acute rejection and BOS, ${ }^{7,8}$ which suggests that it is insufficiently inhibited by maintenance immunosuppression. In vitro experiments have shown that tacrolimus and mycophenolate mofetil inhibited IL-17 production, whereas others reported that cyclosporine and mycophenolate mofetil did not, as discussed by Kim and colleagues. ${ }^{27}$ Data from experimental studies underline the importance of IL-17 in acute rejection and $\mathrm{BO}$, and the efficacy of IL-17 inhibition to counteract rejection, ${ }^{28}$ and AZI therapy represents a step in this direction by reducing the numbers of Tc17 cells in lung tissue.

Interestingly, the numbers of CD8 ${ }^{+}$cells without IL-17 production were relatively high in isografts. An explanation may be that rats have constitutive bronchus-associated lymphoid tissue (BALT) that is not present in humans ${ }^{29}$ and was preserved in isografts. An earlier study using the Brown Norway to Lewis rat lung transplantation model has shown that BALT structure and function were damaged by allograft rejection at 6 months following transplantation but preserved in isografts. ${ }^{30}$ This may have also occurred in our study.

Reduced IL-12 in BAL is a predictive marker for BOS onset in lung-transplanted patients ${ }^{10}$ and tissue IL-12 protein was also decreased at 8 weeks following transplantation in our study. Decrease of IL-12 in BOS could be due to a downregulation of the IL1ra/IL-1 $\beta$ balance that has a profibrotic effect. ${ }^{10}$ AZI prevented the decrease in IL-12 at 8 weeks following transplantation, and IL-12 protein levels 


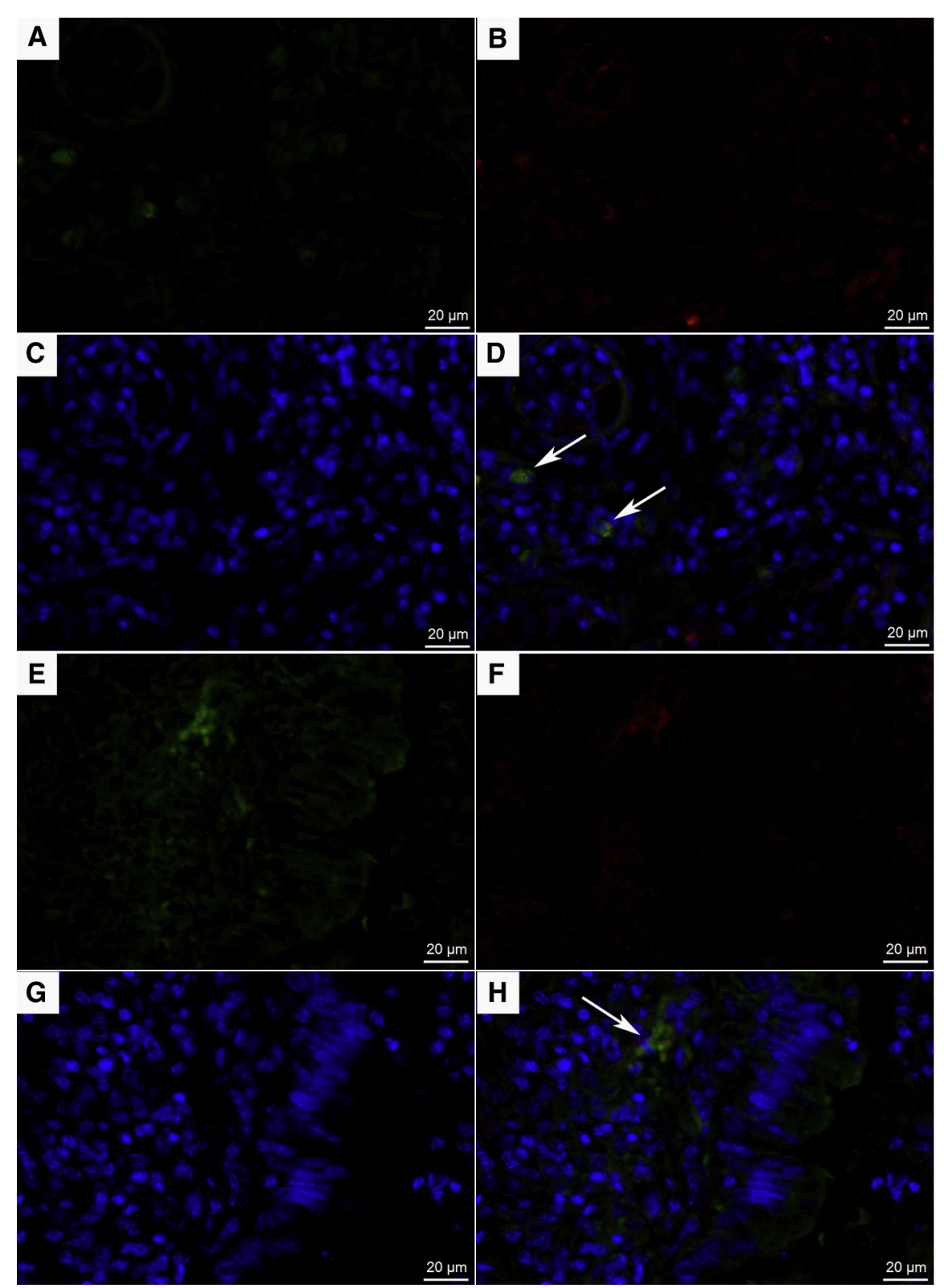

FIGURE 5. Immunofluorescent double-staining of IL-17 and CD8. A-D, Control allograft at 4 weeks: A, IL-17 (green); B, CD8 (red); C, DAPI nuclear staining (blue); D, merged image of IL-17, CD8, and DAPI. E-H, AZI-treated allograft at 4 weeks: E, IL-17 (green); F, CD8 (red); G, DAPI nuclear staining (blue); $\mathrm{H}$, merged image of IL-17, CD8, and DAPI. White arrows indicate $\mathrm{IL}-17^{+} / \mathrm{CD} 8^{+}$double-stained cells, white bars in the lower right corner indicate 20 $\mu \mathrm{m}$, original magnification $\times 400$.

in the AZI group were similar to the isograft group. Also in the AZI+tano group, IL-12 production at 8 weeks was slightly increased versus control allografts and this could have helped to counteract allograft fibrosis in this group. IFN- $\gamma$ was significantly increased in allografts versus isografts at 4 weeks posttransplant, but not at 8 weeks. This is most likely due to acute rejection that is predominant at 4 weeks. At this time point, IL-12 expression was also higher than at 8 weeks posttransplant when profibrotic mechanisms may prevail, particularly in control allografts.
In our study, AZI decreased active MMP-9 levels at 8 weeks following transplantation, but not proMMP-9 expression. In the rat cytokine array AZI also decreased CINC-3, which is the equivalent of IL-8 in rats. This has also been demonstrated in the clinical setting. ${ }^{31}$

Tanomastat was initially developed for oral cancer treatment and blocks active MMPs by a Zn-binding carboxyl group. ${ }^{24}$ It was chosen for our study because it is a global inhibitor of MMPs (MMP-2>MMP-3>MMP-9, MMP-11, MMP-13, and MT1MMP) and was relatively well tolerated 
in clinical studies. ${ }^{32}$ Tanomastat monotherapy for 8 weeks following transplantation did not improve allograft histology (data not shown), so that we investigated if it could enhance the effect of AZI. MMP inhibition to prevent or treat BOS is a controversial subject, because the timing, the types of MMPs inhibited, the dose, and combination with immunosuppression seem to be important for efficacy. ${ }^{33,34}$ In a mouse model of subcutaneous tracheal transplantation, MMP-9 deficiency of the host prevented obliterative airway disease, whereas MMP-2 deficiency did not. ${ }^{35}$ In our model, MMP-2 and MMP-9 expression was not changed by the AZI+tano, but if tanomastat reduced local MMP-2 activity more potently than MMP-9 activity, this may be an explanation for the lack of efficacy of tanomastat alone and the better outcome in combination with AZI, which is an inhibitor of active MMP-9. In addition, tanomastat alone had some proinflammatory effects in the cytokine array, which were only in part counteracted by AZI in the combination therapy group.

Despite significant changes in cytokine levels, the impact of AZI therapy on histologic findings was not significant. In another study using the same model with overexpression of endogenous MMP inhibitors and therapy with the MMP inhibitor COL3, no effect on rejection pathology occurred, despite differences in cytokine expression. ${ }^{33}$ Only the combination of cyclosporine with a low dose of the MMP inhibitor SC080 improved rejection pathology, that is, airway obliteration, in another study. ${ }^{34}$ Interestingly, a clinical study demonstrated decreased plasma levels of proinflammatory cytokines after 12 months of AZI therapy without correlation with response to AZI in pulmonary function tests. ${ }^{36}$ In addition, BAL neutrophilia and increased IL-8 levels reappeared during AZI therapy in lung-transplanted patients with relapsed lymphocytic bronchiolitis, although the number of IL- $17^{+}$cells among submucosal lymphocytes decreased. ${ }^{26}$ This indicates that detectable AZIspecific anti-inflammatory effects may not necessarily be sufficient to improve the outcome of the transplanted lung.

One limitation of our study might be that no immunosuppression was used other than a single dose of prednisolone at transplantation. However, this allows studying specific prophylactic effects of AZI apart from possible drug interactions that are always present in patients. Furthermore, calcineurin inhibitors do not completely block IL-17 production $^{7,8,27}$ so that the findings may also be relevant under immunosuppression. Second, the rat may not be the optimal model because of immunologic differences to humans, and even in the rat model not all animals develop the same degree of BO. In addition, the improvement of histologic scores in the AZI+tano group was not statistically significant due to small sample size $(n=4)$, and cytokine protein expression levels in this group had a large standard deviation so that changes did not reach statistical significance. Only IL-17 and CD8 were evaluated in tissue, and a cell type specific analysis of MMPs or other cytokines was not performed. In addition, the present study cannot account for the possible changes that might have been detected if the lung grafts of the AZI+tano group had been harvested at an earlier time point, for example, at 4 weeks. At the same time, earlier harvest of the tissue, although possibly beneficial for acute rejection-induced changes, might have not allowed BO development that was expected to be targeted by MMP inhibitor therapy in our study.

In summary, the F344-WKY model used in this study successfully depicted BO-specific changes in lung tissue protein expression, including increased active MMP-9 and decreased IL-12 at 8 weeks following transplantation. ${ }^{6,10}$ Furthermore, we show that AZI therapy reduces IL-17 protein expression by reducing numbers of Tc17 lymphocytes in lung allograft tissue, which is not achieved by standard immunosuppression during acute rejection and $\mathrm{BOS}^{7,8}$ Considering the high incidence of BOS in long-term survivors and the limited therapeutic strategies, the combination between AZI and an MMP inhibitor, for example, a specific MMP-9 inhibitor, should be studied further. MMP inhibition in the right dose at the right time and targeting the right MMPs may help to counteract fibrotic remodeling in lung allografts.

We would like to thank Dr M.C. Brüggen (Department of Dermatology, Medical University of Vienna) for technical assistance with immunofluorescence staining.

\section{References}

1. Christie JD, Edwards LB, Kucheryavaya AY, Aurora P, Dobbels F, Kirk R, et al. The Registry of the International Society for Heart and Lung Transplantation: twenty-seventh official adult lung and heart-lung transplant report-2010. $J$ Heart Lung Transplant. 2010;29:1104-18.

2. Todd JL, Palmer SM. Bronchiolitis obliterans syndrome: the final frontier for lung transplantation. Chest. 2011;140:502-8.

3. Bharat A, Kuo E, Steward N, Aloush A, Hachem R, Trulock EP, et al. Immunological link between primary graft dysfunction and chronic lung allograft rejection. Ann Thorac Surg. 2008;86:189-97.

4. Vanaudenaerde BM, Wuyts WA, Geudens N, Dupont LJ, Schoofs K, Smeets S, et al. Macrolides inhibit IL17-induced IL8 and 8-isoprostane release from human airway smooth muscle cells. Am J Transplant. 2007;7:76-82.

5. Verleden SE, Vos R, Mertens V, Willems-Widyastuti A, De Vleeschauwer SI, Dupont LJ, et al. Heterogeneity of chronic lung allograft dysfunction: insights from protein expression in broncho alveolar lavage. J Heart Lung Transplant. 2011;30:667-73

6. Taghavi S, Krenn K, Jaksch P, Klepetko W, Aharinejad S. Broncho-alveolar lavage matrix metalloproteases as a sensitive measure of bronchiolitis obliterans. Am J Transplant. 2005;5:1548-52.

7. Vanaudenaerde BM, Dupont LJ, Wuyts WA, Verbeken EK, Meyts I, Bullens DM, et al. The role of interleukin-17 during acute rejection after lung transplantation. Eur Respir J. 2006;27:779-87.

8. Vanaudenaerde BM, De Vleeschauwer SI, Vos R, Meyts I, Bullens DM Reynders V, et al. The role of the IL23/IL17 axis in bronchiolitis obliterans syndrome after lung transplantation. Am J Transplant. 2008;8:1911-20.

9. Prause O, Bozinovski S, Anderson GP, Linden A. Increased matrix metalloproteinase-9 concentration and activity after stimulation with interleukin-17 in mouse airways. Thorax. 2004;59:313-7.

10. Meloni F, Vitulo P, Cascina A, Oggionni T, Bulgheroni A, Paschetto E, et al. Bronchoalveolar lavage cytokine profile in a cohort of lung transplant recipients: 
a predictive role of interleukin-12 with respect to onset of bronchiolitis obliterans syndrome. J Heart Lung Transplant. 2004;23:1053-60.

11. Saini D, Weber J, Ramachandran S, Phelan D, Tiriveedhi V, Liu M, et al. Alloimmunity-induced autoimmunity as a potential mechanism in the pathogenesis of chronic rejection of human lung allografts. J Heart Lung Transplant. 2011;30: 624-31.

12. Kreisel D, Krupnick AS, Puri V, Guthrie TJ, Trulock EP, Meyers BF, et al. Shortand long-term outcomes of 1000 adult lung transplant recipients at a single center. J Thorac Cardiovasc Surg. 2011;141:215-22.

13. Vanaudenaerde BM, Meyts I, Vos R, Geudens N, De Wever W, Verbeken EK, et al. A dichotomy in bronchiolitis obliterans syndrome after lung transplantation revealed by azithromycin therapy. Eur Respir J. 2008;32:832-43.

14. Kingah PL, Muma G, Soubani A. Azithromycin improves lung function in patients with post lung transplant bronchiolitis obliterans syndrome: a meta-analysis. Clin Transplant. 2014;28:906-10.

15. Vos R, Vanaudenaerde BM, Verleden SE, De Vleeschauwer SI, WillemsWidyastuti A, Van Raemdonck DE, et al. A randomised controlled trial of azithromycin to prevent chronic rejection after lung transplantation. Eur Respir J. 2011;37:164-72.

16. Vos R, Vanaudenaerde BM, Verleden SE, Ruttens D, Vaneylen A, Van Raemdonck DE, et al. Antiinflammatory and immunomodulatory properties of azithromycin involved in treatment and prevention of chronic lung allograft rejection. Transplantation. 2012;94:101-9.

17. Hirt SW, You XM, Moller F, Boeke K, Starke M, Spranger U, et al. Development of obliterative bronchiolitis after allogeneic rat lung transplantation: implication of acute rejection and the time point of treatment. J Heart Lung Transplant. 1999; 18:542-8.

18. von Suesskind-Schwendi M, Hirt SW, Diez C, Ruemmele P, Puehler T, Schmid C, et al. Impact of the severity of acute rejection in the early phase after rat lung transplantation on the effectiveness of mycophenolate mofetil to treat chronic allograft rejection. Eur J Cardiothorac Surg. 2012;42:142-8.

19. von Susskind-Schwendi M, Ruemmele P, Schmid C, Hirt SW, Lehle K. Lung transplantation in the Fischer 344-Wistar Kyoto strain combination is a relevant experimental model to study the development of bronchiolitis obliterans in the rat. Exp Lung Res. 2012;38:111-23.

20. Yasufuku K, Heidler KM, O'Donnell PW, Smith GN Jr, Cummings OW, Foresman BH, et al. Oral tolerance induction by type V collagen downregulates lung allograft rejection. Am J Respir Cell Mol Biol. 2001;25:26-34.

21. Lutz J, Yao Y, Song E, Antus B, Hamar P, Liu S, et al. Inhibition of matrix metalloproteinases during chronic allograft nephropathy in rats. Transplantation. 2005;79:655-61.

22. Yasufuku K, Heidler KM, Woods KA, Smith GN Jr, Cummings OW, Fujisawa T, et al. Prevention of bronchiolitis obliterans in rat lung allografts by type V collagen-induced oral tolerance. Transplantation. 2002;73:500-5.

23. Schmid RA, Stammberger U, Hillinger S, Gaspert A, Boasquevisque $\mathrm{CH}$, Malipiero U, et al. Fas ligand gene transfer combined with low dose cyclosporine A reduces acute lung allograft rejection. Transpl Int. 2000;13(Suppl 1):S324-8.
24. Zucker S, Cao J, Chen WT. Critical appraisal of the use of matrix metalloproteinase inhibitors in cancer treatment. Oncogene. 2000;19:6642-50.

25. Verleden SE, Vos R, Vandermeulen E, Ruttens D, Vaneylen A, Dupont LJ, et al. Involvement of interleukin-17 during lymphocytic bronchiolitis in lung transplant patients. J Heart Lung Transplant. 2013;32:447-53.

26. Vanaudenaerde BM, Verleden SE, Vos R, De Vleeschauwer SI, WillemsWidyastuti A, Geenens R, et al. Innate and adaptive interleukin-17-producing lymphocytes in chronic inflammatory lung disorders. Am J Respir Crit Care Med. 2011;183:977-86.

27. Kim HY, Cho ML, Jhun JY, Byun JK, Kim EK, Yim YB, et al. The imbalance of T helper 17/regulatory $\mathrm{T}$ cells and memory B cells during the early posttransplantation period in peripheral blood of living donor liver transplantation recipients under calcineurin inhibitor-based immunosuppression. Immunology. 2013;138:124-33.

28. Fan L, Benson HL, Vittal R, Mickler EA, Presson R, Fisher AJ, et al. Neutralizing IL-17 prevents obliterative bronchiolitis in murine orthotopic lung transplantation. Am J Transplant. 2011;11:911-22.

29. Randall TD. Bronchus-associated lymphoid tissue (BALT) structure and function. Adv Immunol. 2010;107:187-241.

30. Winter JB, Prop J, Groen M, Petersen AH, Uyama T, Meedendorp B, et al. Defective bronchus-associated lymphoid tissue in long-term surviving rat lung allografts. Am J Respir Crit Care Med. 1995;152:1367-73.

31. Verleden SE, Vandooren J, Vos R, Willems S, Dupont LJ, Verleden GM, et al. Azithromycin decreases MMP-9 expression in the airways of lung transplant recipients. Transpl Immunol. 2011;25:159-62.

32. Hirte H, Vergote IB, Jeffrey JR, Grimshaw RN, Coppieters S, Schwartz B, et al. A phase III randomized trial of BAY 12-9566 (tanomastat) as maintenance therapy in patients with advanced ovarian cancer responsive to primary surgery and paclitaxel/platinum containing chemotherapy: a National Cancer Institute of Canada Clinical Trials Group Study. Gynecol Oncol. 2006;102: 300-8.

33. Yoshida S, Iwata T, Chiyo M, Smith GN, Foresman BH, Mickler EA, et al. Metalloproteinase inhibition has differential effects on alloimmunity, autoimmunity, and histopathology in the transplanted lung. Transplantation. 2007;83: 799-808.

34. Sato M, Hwang DM, Guan Z, Yeung JC, Anraku M, Wagnetz D, et al. Regression of allograft airway fibrosis: the role of MMP-dependent tissue remodeling in obliterative bronchiolitis after lung transplantation. Am J Pathol. 2011;179: $1287-300$.

35. Fernandez FG, Campbell LG, Liu W, Shipley JM, Itohara S, Patterson GA, et al. Inhibition of obliterative airway disease development in murine tracheal allografts by matrix metalloproteinase-9 deficiency. Am J Transplant. 2005;5: 671-83.

36. Meloni F, Solari N, Morosini M, Cascina A, Oggionni T, Bini F, et al. Clinical and immunological evaluation of 12-month azithromycin therapy in chronic lung allograft rejection. Clin Transplant. 2011;25: E381-9.

Readers who found these articles interesting may also like to read the following papers found in recent and future issues of our sister publications, Seminars in Thoracic and Cardiovascular Surgery and Operative Techniques in Thoracic and Cardiovascular Surgery!

State of the Art: Richard Weisel. The Promise and Challenges of Cardiac Stem Cell Therapy. Semin Thorac Cardiovasc Surg. Spring 2014;26(1):44-52. 